nerves inhibiting intestinal peristalsis. If this should be confirmed, then it would be proven that at least three symptoms of fever, the quickened respiration and pulse and the constipation, are direct effects of elevated temperature.

When we consider the important nutritive changes in the muscle accompanying increased thermogenesis we shall be inclined to attribute to these alterations and the associated abnormal innervation, rather than to increased temperature, the muscular pains and weakness which form such an early and frequent complaint in fevers.

The investigations hitherto published of changes in the blood produced by increased temperature within febrile limits are not of sufficiently definite and satisfactory nature to warrant any consideration on the present occasion.

Nor am I acquainted with any positive experimental evidence (save Bokai's work already mentioned) that increased temperature is concerned in the production of the digestive disorders of fever. It has already been said that the rabbits with high internal temperatures in the hot box ate greedily, but these voracious animals cannot be considered favorable subjects to test this question.

Especial emphasis has been laid by Liebermeister and those who accept his teachings, upon the dependence of the nervous symptoms of fever, particularly the so-called typhoid symptoms, on the elevation of temperature. There is, however, abundant clinical evidence to disprove this doctrine. Reference need be made only to relapsing fever, and especially to the aseptic fever described by Genzmer and Volkmann, in which there is entire absence of the whole group of so-called nervous symptoms. Moreover, Liebermeister's opinion in this respect is not supported by adequate experimental evidence. Unless the temperature of the brain or of the entire animal be brusquely raised to a high point by coarse methods no disturbance of the cerebral functions is noticed until the temperature reaches a critical point, beyond which further increase is likely to prove rapidly fatal. At this critical point the animal, which before has lain quietly, becomes very uneasy, and if the temperature rises higher it has convulsions and coma, and dies.

I have endeavored to bring before you in this lecture the experimental evidence relating to the effects of increased temperature upon the general condition of the body, and upon the functions of its various organs. I have given account, as briefty as possible, of some experiments which perhaps shed additional light upon this important subject. In the course of this lecture emphasis has repeatedly been laid upon the necessity of controlling the results of the experimental method by clinical observation, and here and there I have endeavored to institute this control. Further than this I shall not attempt to set before you the clinical evidence regarding the effects of increased temperature in fever. There are those here more competent than I to deal with this side of the question. We may feel assured that when all the facts are before us, and are properly interpreted there can be no lack of harmony between the results of experimental and those of clinical investigations.

- A Chemical Analysis, published in the Druggists Circular, accuses the extensively-advertised Scotch Oats Essence of containing alcohol and morphia.

\section{Briginal altitieg.}

FRACTURE OF THE STERNUM, WITH DISLOCATION OF FRAGMENTS; RESTORATION TO PLACE BY TREATMENT BY POSITION; RECOVERY.

BY CHARLEs B. PORTER, M.D.,
Professor of Clinical Surgery Harvard Medical School, Surgeon Massachusetts General Hospital.

Fracture of the sternum alone is an extremely rare accident, but as a complication in crushing injuries of the thorax it is associated with fracture of the spine or ribs. At St. George's Hospital in four years vine cases were examined, three associated with fracture of the spine, and six with fractured ribs. Malgaigne recorded but ten cases, five of which ended fatally on account of complications as mentioned above. The causes are usually direct violence, as crushing blows upon the chest, though violent bending of the spine backwards has produced it. "One case (Chevance's) was caused by violent forward flexing of the body from a fall."

Dr. Fagel, of Mexico, reports this accident as having happened to a celebrated vaulter, who whilst bending his body backward, was endeavoring to raise a heavy weight with his teeth. The complications are injury and inflammation of the pericardium, pleura, lungs, mediastinum and heart.

Authorities differ as to treatment advised. Some recommend the recumbent position, with a pad between the scalpulæ, and head low. Others the sitting posture, with the head thrown back. Others operative measures, as the lifting of the depressed fragment by means of the trephine and elevator, or the corkscrew ; while another says that these latter methods are "the relics of the old, cruel and barbarous surgery." It seems to me that after position and manipulation have failed, and deep inflammation threatens, that some operative interference is indicated, and especially if the displaced fragment is pressing upon the treachea, or the large vessele.

The case which I have to report is that of Captain Holden, aged twenty-one, captain of the Harvard football eleven, and I give the name as, at the time of the accident (one of the intercollegiate games), it became generally known through the papers. Captain Holden stood erect ready to tackle one of the opposing team, who was running with the ball. As his opponent reached him he jumped, and his knee struck Holden on the sternum, producing a fracture and dislocation of the upper fragment backwards, the lower one overriding. The point of fracture was at the junction of the second and third pieces of the gladiolus. The ossification at this point is completed between the twentieth and twenty-fifth years of age, so that the separation was of the nature of an epiphysial fracture. There was profound shock and agonizing pain. The depression seemed to be little more than the thickness of the sternum. He was removed to the Massachusetts General Hospital, and in consultation with the other members of the staff it was decided to try the effect of the recumbent position, with hard pad between the shoulder blades, and the head lower than the chest. This position was most painful, and after some hours the pad was removed.

On the next day there was no change in the position, and the patient suffered greatly from pain in the 
bowels, which did not yield to cathartics or enemata. $\mathrm{He}$ had retention, requiring the catheter. Morphine was given subcutaneously.

On the third day no change. The patient was lifted from the bed to the erect position, and, supported under either arm, was bent backwards as far as possible. This produced a sickening pain at seat of injury, and he feared he would faint, and he was put back to bed. About half an hour afterwards, on coughing and taking a deep respiration, the bone suddenly snapped forward into place. A broad band plaster was immediately applied (such as is used in fracture of the ribs) to bold the chest walls immovable, and compel diaphragmatic respiration. The plaster was changed from time to time, and there was no re-displacement. There was slight cough for ten days. Eleven days after injury he was up, and in three weeks left the hospital. There was no resulting deformity.

\section{DISLOCATION OF THE BONES OF THE STER- NUM.}

BY C. B. LYMAN, M.D., DENVER, COL.

Assistant Surgeon, Union Pacific Railroad.

THE patient, a passenger brakeman on the Union Pacific Railroad, was twenty-seven years old. On January 22d, while running up an embankment to catch a train, and when nearly at the top, he fell, and struck with his chest upon the end of a projecting tie. He suffered a good deal of pain during the day, and with every breath or movement of the body, he felt something snap at the seat of pain.

I first saw him on January 25 th, three days after the accident; the pain had diminished, but he could still feel the snapping. Upon examination I found a depression of nearly half an inch just below the line of the second ribs, and in the median line; with forced inspiration there was a distinct cartilaginous grating. In fact, I had to do with a backward dislocation of the gladiolus upon the manubrium, the second rib on each side remaining attached to the manubrium.

Reduction was attempted by manipulation of the fragments, and also by standing behind the patient and drawing the shoulders back forcibly, while the patient was made to take a deep inspiration. This, however, failed. The patient was then taken to the Union Pacific Hospital and etherized; the dislocation was then reduced by Jr. O. J. Pfeiffer and myself by depressing the upper fragment firmly, while pressure was being exerted upon the chest in the axillary line on either side, over the ribs which were attached to the lower fragment, the object being to spring the lower fragment forward at the same moment that the upper fragment was most depressed.

This failed several times; but finally, the patient most opportunely gave a slight cough, owing to fresh ether on the sponge, just at the moment when pressure was being exerted as described, and the lower fragment came forward into line with a distinct crepitus. An adhesive strip was then placed around the chest to hold the fragments immobile for a few days. There has been no tendency to re-dislocation, and the fragments remain in perfect line. This case is of interest for several reasons:

(1) On account of the infrequency of the accident. Poland, in "Holmes's System," says that during the last thirty years "several cases" have been seen at Guy's Hospital.

(2) Its method of production. Most of the cases reported, have been produced by indirect violence; this was produced by direct violence, the end of the tie striking the sternum just below the line between the manubrium and the gladiolus.

(3) Because the lower fragment was displaced backwards. In almost every case on record the upper fragment has been displaced backward instead of the lower one.

\section{RECENT PROGRESS IN PUBLIC HYGIENE.}

BY SAMUEL W. ABBOTT, M.D.

\section{THE ACTION OF DIFFERENT WATER-SUPPLIES CPON LEAD-PIPES. ${ }^{1}$}

SheFfield, in England, has a population of about 300,000 . It is supplied with water from several reservoirs, being of moorland origin and furnished by gravity. The high service of the town is furnished from a separate reservoir. Cases of lead-poisoning have been frequent in the town, and there has been an alarming increase of such cases during the past winter, the recent cases amounting to several hundred. On inquiry it was found that these were quite exclusively among the population supplied from the highservice reservoir. The waters of these reservoirs are obtained from different districts; and in the case of the lower-level water the amount of lead per gallon has usually been but a trace only, never more than $\frac{1}{10}$ grain even after standing in the pipes all night, while that in the higher-level water has often been found to be as high as $\frac{1}{2}$ grain per gallon, and occasionally as much as $1 \frac{1}{4}$ grains.

'The water of the high-service was found to be distinctly acid, and it was claimed that the acid was of vegetable origin, arising from the peat upon the moors.

Certain differences in the character of the supplies may account for the variable action of the water upon lead.

The low-level supply is obtained partly from a reservoir, the water in which has been stored for a long time, and the water of this supply also passes for two miles through a brick conduit, the mortar of which may cause the neutralization of the free acid. These, however, are mere conjectures, since no systematic inquiry has been made. The water company has had blocks of limestone placed in the conduit. Mr. Allen, the public analyst, criticizes this measure, saying that the use of too much limestone will injure the water, and render it as liable to act upon lead as if it had not been thus treated. He says, moreover, that the only rational method of using lime is to introduce it regularly and constantly in powder, or as milk of lime, in such quantity as previous analysis shall have shown to be requisite for the neutralization of the free acid.

The panic produced by this epidemic of lead-poisoning was followed by an alarming waste of water, the taps being kept open for hours at a time. The filter manufacturers drove a lively trade, since it was found that animal charcoal seemed capable of removing lead from the water, probably, as the writer states, in con1 The Sheftield Water-Supply and Lead-poisoning. By Alfred H.
Allen, F.C.S. Sanitary Record, Feb. 15, 1888, p. 356. 